\title{
VAI TRÒ CỦA CDIO TRONG BỐI CẢNH ĐỔI MỚI CHƯƠNG TRÌNH ĐÀO TẠO THEO OBE VÀ KIỀM ĐỊNH ABET

\author{
Trần Nhật Tân ${ }^{(*)}$
}

(*) Tiến sĩ. Đại học Duy Tân.Email: trannhattan@duytan.edu.vn.

DOI: $10.37550 /$ tdmu.CFR/2021.01.134

\section{Tóm tắt}

Ngày nay, do nhũng tiến bộ không ngùng về công nghệ, kinh tế và xã hội cũng nhu các yêu cầu ngày càng cao tù̀ các doanh nghiệp đối với các sinh viên mói ra trương, các trường đại học đang đối mặt với nhũng thách thức phải nâng cao chất lượng đào tạo. Với nguồn lực hạn chế, các trương đại học của Việt Nam cần chọn giải pháp phù hợp nhất là tái cấu trúc các churong trình đào tạo. Một trong nhũng nhiệm vu quan trọng trong việc tái cấu trúc chuong trình đào tạo hiện nay là chuyển chwơng trình đào tạo tù định hướng nội dung (Content Based) sang định huớng đầu ra (Outcomes Based). Bài báo này chia sẻ một số khía cạnh về viẹc áp dụng C-D-I-O nhu là bối cảnh, vận dụng CDIO và OBE nhu là triết lý và công cu để triển khai, cũng như sủ dụng định hướng kiểm định ABET và các kiểm định khác nhu là động lực nhằm cải tiến chương trình đào tạo đáp úng các nhu cầu của doanh nghiệp và xã hội.

Từ khoá: $C D I O, O B E, A B E T$

\section{1. Đặt vấn đề}

CDIO Initiative là một khung giáo dục sáng tạo nhằm đào tạo ra các thế hệ kỹ sư trong kỷ nguyên mới. Mô hình giáo dục theo CDIO với mục tiêu cung cấp cho sinh viên một nền tảng giáo dục về kỹ thuật với trọng tâm được đặt trong bối cảnh người học cần thành thạo về quá trình Hình thành ý tưởng - Thiết kế giải pháp - Triển khai - Vận hành $(\mathrm{C}$ D-I-O) các hệ thống, phải pháp và sản phẩm nhằm đáp ứng các yêu cầu của doanh nghiệp, xã hội trong thế giới thực [1].

Giáo dục kỹ thuật và các yêu cầu thực tế đối với người kỹ sư trong những năm gần đây đã khác xa với các thập kỷ trước. Nhận thấy yêu cầu cấp thiết cần phải thu hẹp khoảng cách đang ngày càng gia tăng này, các trường đào tạo kỹ thuật hàng đầu ở Mỹ, Châu Âu, Canada, Anh, Châu Phi, Châu Á và New Zealand đã thành lập Sáng kiến CDIO. Đây là sự hợp tác ở quy mô trên toàn thế giới nhằm hình thành và phát triển một tầm nhìn mới về giáo dục kỹ thuật [1]. 
Mô hình giáo dục CDIO dựa trên bối cảnh rằng sinh viên tốt nghiệp các ngành kỹ thuật phải có khả năng: Hình thành ý tưởng - Thiết kế - Triển khai - Vận hành các hệ thống, giải pháp kỹ thuật phức tạp, đem lại giá trị gia tăng trong môi trường kỹ thuật hiện đại dựa trên các nhóm làm việc nhằm tạo ra các hệ thống, giải pháp và sản phẩm.

Tầm nhìn của mô hình giáo dục dựa trên CDIO nhấn mạnh đến các nguyên tắc cơ bản của giáo dục kỹ thuật và đặt trong bối cảnh Hình thành - Thiết kế - Triển khai - Vận hành các hệ thống, giải pháp và sản phẩm như:

- Chương trình đào tạo được tổ chức dựa xung quanh bởi các môn học hỗ trợ lẫn nhau, với các hoạt động C-D-I-O có tính đan xen cao

- Cung cấp đa dạng các dự án thiết kế - triển khai - thử nghiệm cho người học

- Tích hợp các kỹ năng nghề nghiệp như khả năng làm việc nhóm và kỹ năng giao tiếp

- Cung cấp môi trường học tập tích cực và trải nghiệm

- Không ngừng cải tiến thông qua quy trình đảm bảo chất lượng

\subsection{Bối cảnh - Tiêu chuẩn 1 (CDIO Standards)}

Mô hình giáo dục theo CDIO nhấn mạnh đến nguyên tắc cơ bản đầu tiên rằng, các chương trình đào tạo kỹ thuật cần phải đặt quá trình phát triển và triển khai vòng đời của một sản phẩm, quy trình và hệ thống (quy trình Hình thành ý tưởng - Thiết kế - Triển khai thực hiện - Vận hành) làm bối cảnh cho việc xây dựng và cải tiến chương trình đào tạo [2].

Chương trình đào tạo theo $\mathrm{CDIO}$ cần dựa trên nguyên tắc rằng, phát triển và triển khai vòng đời của sản phẩm, quy trình và hệ thống là bối cảnh thích hợp nhất cho giáo dục kỹ thuật. Chu trình Hình thành ý tưởng - Thiết kế - Triển khai - Vận hành chính là mô hình của toàn bộ vòng đời của bất kỳ sản phẩm, quy trình và giải pháp hệ thống nào. Giai đoạn Hình thành ý tưởng bao gồm việc xác định các nhu cầu của khách hàng; xem xét công nghệ, chiến lược của doanh nghiệp và các quy định khác; cũng như phát triển các quy trình kỹ thuật và kế hoạch kinh doanh. Giai đoạn Thiết kế tập trung vào việc tạo ra các thiết kế bao gồm các kế hoạch, bản vẽ và thuật toán mô tả những gì sẽ được thực hiện. Giai đoạn Triển khai đề cập đến việc chuyển đổi các thiết kế thành sản phẩm mẫu, quy trình hoặc hệ thống các giải pháp, bao gồm sản xuất, mã hóa, thử nghiệm và xác nhận tính phù hợp. Giai đoạn cuối cùng Vận hành bao gồm việc sử dụng các sản phẩm hoặc quy trình, giải pháp đã thực hiện nhằm mang lại các giá trị dự kiến, bao gồm quá trình duy trì, phát triển và ngừng hoạt động cua một hệ thống.

Vòng đời của một sản phẩm, quy trình hoặc hệ thống được chọn là bối cảnh cho giáo dục kỹ thuật bởi lẽ nó là một phần của môi trường văn hóa mà trong đó các kiến thức về kỹ thuật và các kỹ năng khác được giảng dạy, thực hành và rèn luyện. Bản chất của nghề kỹ sư là các kỹ sư cần phải có năng lực về Hình thành ý tưởng - Thiết kế - Triển khai - Vận hành các sản phẩm, giải pháp, quy trình và hệ thống kỹ thuật phức tạp trong môi trường làm việc dựa trên các nhóm cộng tác. Trong bất kỳ tổ chức hay doanh nghiệp nào, người kỹ sư cũng 
sẽ phải tham gia vào các quá trình phát triển kỹ thuật, đóng góp vào sự phát triển của các sản phẩm kỹ thuật tuân theo các tiêu chuẩn kỹ thuật và nghề nghiệp.

\subsection{Tiêu chuẩn về Chuơng trình đào tạo kỹ thuật theo ABET (Tiêu chuẩn 5)}

Các chương trình đào tạo kỹ thuật được yêu cầu bắt buộc phải có ít nhất một trải nghiệm thiết kế một hệ thống, sản phẩm nhằm chuẩn bị cho sinh viên trước các yêu cầu trong bối cảnh về thực hành kỹ thuật của nghề kỹ sư. Trải nghiệm thiết kế-triển khai-vận hành giải pháp kỹ thuật hoặc sản phẩm phải được kết hợp với các yêu cầu về tiêu chuẩn kỹ thuật nghề nghiệp trong bối cảnh có các ràng buộc, đồng thời phải dựa trên các kiến thức và kỹ năng có được trong một chương trình đào tạo tích hợp [3].

\subsection{Khung trình độ quốc gia Việt Nam (VQF)}

Hiện nay, Bộ giáo dục và đào tạo đang triển khai khung trình độ quốc gia Việt Nam (VQF) theo Quyết định số 436/QĐ-TTg của Thủ tướng Chính phủ. Khung trình độ quốc gia Việt Nam cho giáo dục đại học được hiểu là những chuẩn mực tối thiểu, là bộ tiêu chí với khối lượng, chuẩn đầu ra của từng ngành đào tạo, yêu cầu kiến thức, kĩ năng, thái độ, tiệm cận theo các tiêu chuẩn của các nước trong khu vực và trên thế giới, phù hợp với yêu cầu cho từng lĩnh vực ngành nghề nhằm quản lý chất lượng nguồn nhân lực.

Bộ giáo dục và đào tạo xác định mục đích xây dựng khung trình độ quốc gia Việt Nam nhằm giúp các cơ sở giáo dục xây dựng và triển khai các chương trình đào tạo theo hướng tiếp cận hiện đại. Các mục tiêu được xác định cụ thể như:

- Định hướng cho việc xây dựng và phát triển chương trình tại các trường; giúp các trường điều chỉnh cách xây dựng và triển khai chương trình đào tạo từ định hướng nội dung (Content Based) sang định hướng đầu ra (Outcomes Based), đáp ứng nhu cầu doanh nghiệp, bảo đảm chất lượng đào tạo;

- Gắn kết chặt chẽ với quá trình Bảo đảm chất lượng, tạo thuận lợi cho tự đánh giá và cải tiến chương trình tại các cơ sở giáo dục đại học, đồng thời giúp các Trung tâm kiểm định có cơ sở để đánh giá các chương trình chính xác hơn;

- Thúc đẩy thực hiện tham chiếu giữa Khung trình độ quốc gia Việt Nam và Khung tham chiếu trình độ của các quốc gia ASEAN (AQRF), làm cơ sở thực hiện công nhận lẫn nhau về trình độ, nâng cao chất lượng và năng lực cạnh tranh trong đào tạo nguồn nhân lực của Việt Nam so với các nước ASEAN

\section{CDIO + OBE là triết lý và công cụ triển khai}

\subsection{Các tiêu chuẩn CDIO (CDIO Standards)}

CDIO cung cấp cho các trường đại học một bộ tiêu chuẩn trong đó bao gồm việc giải thích các lí do cũng như cung cấp các chỉ dẫn cần thiết trong việc xây dựng và cải tiến chương trình đào tạo kỹ thuật. CDIO cũng cung cấp bộ tiêu chí tự đánh giá nhằm hỗ trợ các trường trong quá trình rà soát và tự đánh giá hiện trạng cũng như quá trình cải tiến liên tục 
chương trình đào tạo của mình. Hình 1. mô tả sơ đồ quy trình vận dụng mô hình CDIO trong quá trình xây dựng và cải tiến chương trình đào tạo.

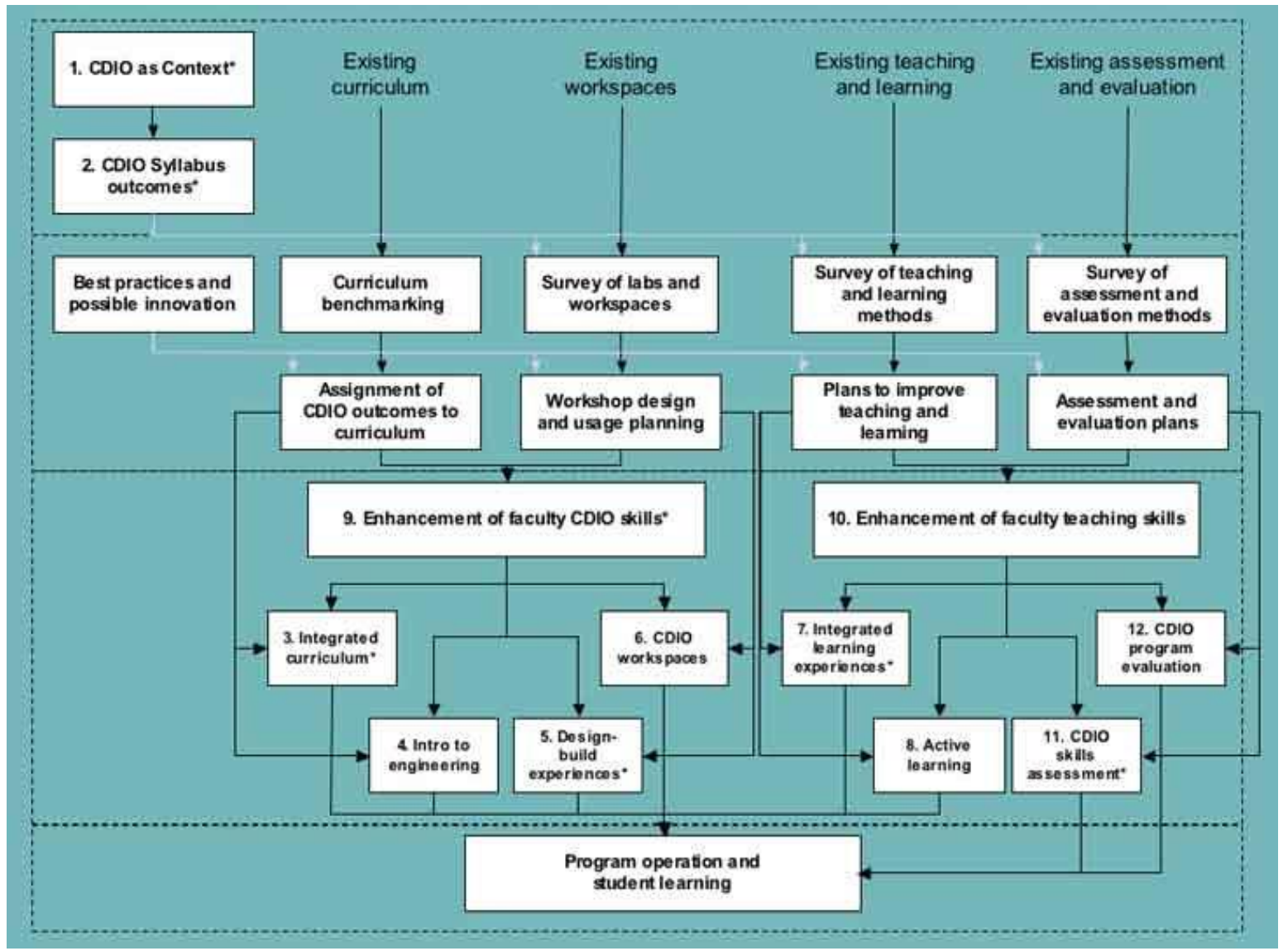

Hình 1. So đồ minh hoạ quy trình vận dụng mô hình CDIO trong xây dụng và cải tiến chuoong trình đào tạo [1]

Quy trình vận dụng mô hình $\mathrm{CDIO}$ trong xây dựng và cải tiến chương trình đào tạo được triển khai từ trên xuống dưới. Các bước triển khai bao gồm:

- Đầu tiên là áp dụng nguyên tắc CDIO làm bối cảnh của chương trình đào tạo kỹ thuật (Tiêu chuẩn 1)

- Tiếp theo sau đó là quá trình xác định Chuẩn đầu ra của chương trình đào tạo (bao gồm các kết quả học tập mong đợi cũng như các kỹ năng liên quan) được nêu trong CDIO Syllabus (Tiêu chuẩn 2). Hai bước này nhằm thiết lập bối cảnh, mục tiêu đào tạo và các chuẩn đầu ra của chương trình đào tạo.

- Bước tiếp theo là thiết lập các đánh giá hiện trạng của chương trình đào tạo đang vận hành bằng cách rà soát chương trình đào tạo theo bốn nhóm nội dung: Chương trình giảng dạy; Không gian học tập trải nghiệm và triển khai các đồ án thiết kế - triển khai - vận hành; Các phương pháp giảng dạy và học tập; và Các phương pháp, công cụ kiểm tra đánh giá chương trình đào tạo/môn học.

- Sau đó, trong mỗi nhóm trong số bốn nhóm nội dung này, chương trình sẽ xác định các nội dung cần cải tiến cũng như thiết kế/điều chỉnh các vấn đề có liên 
quan đến chương trình đào tạo nhằm đáp ứng mục tiêu mong muốn. Khi thực hiện điều này, chương trình đào tạo sẽ vận dụng các yêu cầu được nêu trong Tiêu chuẩn $3-8$, Tiêu chuẩn 11 và 12. Các lĩnh vực cải tiến trong sơ đồ quy trình vận dụng CDIO được thiết lập theo hướng tương hỗ ngang - dọc theo bốn chủ đề: Chương trình giảng dạy - Không gian học tập trải nghiệm và triển khai các đồ án thiết kế - triển khai - vận hành - Phương pháp giảng dạy và học tập - Công cụ và quy trình đánh giá.

- Và cuối cùng, để đạt được mục tiêu của mình, các chương trình đào tạo sẽ thấy rằng cần phải cải tiến liên tục chương trình đào tạo thông qua quá trình nâng cao năng lực của giảng viên về sự hiểu biết cũng như các kỹ năng $\mathrm{CDIO}$, cũng như trong công tác giảng dạy, học tập, và đánh giá (Tiêu chuẩn 9 và 10 ).

\subsection{Chương trình đào tạo tích hợp (Tiêu chuẩn 3)}

Một trong những thách thức lớn nhất trong việc đổi mới các chương trình đào tạo kỹ thuật hiện nay có lẽ là việc tái cấu trúc và cải tiến chương trình đào tạo kỹ thuật đang có trở thành một chương trình giảng dạy tích hợp theo định hướng CDIO (Tiêu chuẩn 3). Chương trình giảng dạy kỹ thuật đòi hỏi cần được thiết kế với các học phần hỗ trợ lẫn nhau một cách logic, với một lộ trình học tập rõ ràng nhằm tích hợp các kỹ năng cá nhân và tập thể cũng như các kỹ năng về thiết kế, xây dựng sản phẩm, quy trình và hệ thống [4].

"Một chương trình giảng dạy tích hợp bao gồm các trải nghiệm học tập nhằm giúp người học đạt được các kỹ năng cá nhân và tập thể, cũng như các kỹ năng về thiết kế, xây dựng sản phẩm, quy trình và hệ thống (Chuẩn đầu ra CDIO Syllabus - Tiêu chuẩn 2), đan xen với việc học tập các kiến thức chuyên ngành và ứng dụng của nó trong nghề nghiệp kỹ thuật. Các học phần chuyên ngành hỗ trợ lẫn nhau bằng cách tạo ra các mối liên hệ rõ ràng giữa các nội dung có liên quan và chuẩn đầu ra của chương trình đào tạo. Một ma trận về mối liên hệ giữa các môn học, môn học - chuẩn đầu ra của chương trình, cũng như kế hoạch học tập rõ ràng sẽ giúp cho việc kết nối các kỹ năng cũng như các nội dung lẫn nhau. Chương trình đào tạo cần được thiết kế để các môn học được đảm bảo ánh xạ đầy đủ đến các chuẩn đầu ra của chương trình đào tạo".

Các kinh nghiệm cho thấy, để xây dựng một chương trình đào tạo tích hợp hiệu quả thì quá trình xác định chuẩn đầu ra của chương trình đào tạo một cách rõ ràng cũng như phân bố hợp lý các đồ án trải nghiệm - thiết kế là việc hết sức quan trọng. Khi các chuẩn đầu ra được xác định rõ ràng, chương trình đào tạo sẽ tái cấu trúc các học phần nhằm đảm bảo các môn học ánh xạ một cách đầy đủ đến các chuẩn đầu ra. Việc xác định và phân bổ hợp lý các đồ án trải nghiệm thiết kế - triển khai cũng như đồ án lớn (đồ án tốt nghiệp) sẽ giúp cho việc sắp xếp dễ dàng các học phần toán và khoa học - cơ sở ngành - chuyên ngành xoay quanh các đồ án này.

"Nhà trường đã áp dụng một chương trình đào tạo được xây dựng dựa trên việc giảng dạy tích hợp các dự án xuất sắc nhằm hỗ trợ cho sinh viên lĩnh hội được các kiến thức thông qua việc chủ động khám phá những thách thức và giải quyết các vấn đề thực tiễn của thế giới. Việc giảng dạy kỹ thuật dựa trên dự án được vận hành theo mô hình CDIO (Conceive - Design - Implement - Operate). Đây là một mô hình giáo dục kỹ thuật tiên tiến 
nhằm dạy cho sinh viên - những kỹ sư tương lai các nguyên tắc cơ bản về kỹ thuật để họ có thể hình thành nên các kỹ năng về xây dựng ý tưởng, thiết kế, triển khai thực hiện và vận hành các thiết kế kỹ thuật cũng như đưa ra các giải pháp trong thế giới thực" - Đánh giá của $\mathrm{ABET}$ về Điểm mạnh của chương trình đào tạo Công nghệ kỹ thuật Điện Điện tử tại Đại học Duy Tân.

\section{3. Đồ án trải nghiệm Thiết kế - Triển khai (Tiêu chuẩn 5)}

Học tập dựa trên dự án là một phương pháp giảng dạy tiên tiến trong đó người học trải nghiệm một loạt các kỹ năng và chủ đề trong quá trình tạo ra các dự án của riêng họ. Thông thường, những dự án trải nghiệm này là các giải pháp cho một vấn đề xuất hiện từ các yêu cầu thực tế của doanh nghiệp và xã hội. Và điều quan trọng nhất trong học tập dựa trên trải nghiệm dự án là người học sẽ học trong quá trình làm ra một thứ gì đó (sản phẩm, giải pháp, hệ thống). Người học sẽ được trải nghiệm làm việc theo nhóm và mang kinh nghiệm, khả năng, phong cách học tập và quan điểm của riêng họ vào dự án. Mô hình giáo dục theo CDIO khuyến cáo rằng, một chương trình giảng dạy kỹ thuật cần bao gồm ít nhất hai đồ án trải nghiệm thiết kế triển khai, trong đó một ở cấp độ cơ bản và một ở cấp độ nâng cao [5].

Trải nghiệm thiết kế - triển khai là một loạt các hoạt động kỹ thuật trọng tâm của quá trình phát triển các sản phẩm và hệ thống mới. Đồ án trải nghiệm thiết kế-triển khai bao gồm tất cả các hoạt động được mô tả trong quy trình C-D-I-O ở giai đoạn $\mathrm{D}$ và $\mathrm{I}$, cộng với các khía cạnh thích hợp của việc hình thành tư tưởng ở giai đoạn $\mathrm{C}$. Người học sẽ phát triển các kỹ năng xây dựng sản phẩm, quy trình và hệ thống, cũng như khả năng áp dụng các nguyên lý kỹ thuật và khoa học trong các đồ án trải nghiệm thiết kế-triển khai được tích hợp vào chương trình giảng dạy. Trải nghiệm thiết kế - triển khai được xem là cơ bản hoặc nâng cao khi xét đến khía cạnh phạm vi, độ phức tạp và trình tự của chúng trong chương trình. Các trải nghiệm thiết kế - triển khai một sản phẩm và hệ thống đơn giản được đưa vào chương trình ở những năm đầu tiên, trong khi các trải nghiệm thiết kế - triển khai phức tạp hơn được thiết kế ở năm 3 hay năm 4 . Các đồ án trải nghiệm - thiết kế được sắp xếp để giúp người học có thể vận dụng các kiến thức và kỹ năng có được trong các môn học cũng như những trải nghiệm học tập đã học trước đó. Các trải nghiệm về hình thành ý tưởng thiết kế - triển khai - vận hành các sản phẩm, quy trình và hệ thống cũng có thể được tích hợp thông qua các dự án nghiên cứu hoặc các đồ án thực tập tại doanh nghiệp.

Các trải nghiệm về thiết kế - triển khai cần được thực hiện một cách có cấu trúc và trình tự hợp lý nhằm thúc đẩy người học đạt được những yêu cầu ban đầu trong quá trình thực hành kỹ thuật sau này. Việc lặp lại các trải nghiệm thiết kế - triển khai cũng như tăng dần độ phức tạp của các đồ án nhằm củng cố sự hiểu biết của người học về quá trình phát triển một sản phẩm, quy trình và hệ thống. Các đồ án trải nghiệm về thiết kế - triển khai cũng cung cấp một nền tảng vững chắc để xây dựng sự hiểu biết sâu hơn về các khái niệm và kỹ năng trong ngành nghề. Việc chú trọng vào kỹ năng xây dựng một sản phẩm và thực hiện các quy trình thông qua trải nghiệm các dự án từ yêu cầu thực tế sẽ mang lại cho sinh viên cơ hội kết nối giữa các kiến thức về kỹ thuật mà họ đang học với ngành nghề mà họ lựa chọn.

Một trong những thực hành tốt mà các chương trình kỹ thuật đang vận dụng là xây dựng hệ thống các đồ án trải nghiệm thiết kế - triển khai xuyên suốt từ năm nhất đến năm cuối. 
“Chương trình đào tạo Công nghệ kỹ thuật Điện Điện tử tại Đại học Duy Tân đã tích hợp những nguyên tắc của $\mathrm{CDIO}$ trải dài trong 5 môn học đồ án trải nghiệm thiết kế - triển khai. Đội ngũ giảng viên của chương trình đã thể hiện năng lực và khả năng thực hiện các nguyên tắc CDIO trong chương trình giảng dạy một cách xuất sắc thông qua các báo cáo trình bày tại nhiều hội nghị về CDIO trên toàn thế giới. Sinh viên của chương trình đã được chuẩn bị tốt cho việc thực hành kỹ thuật thông qua quá trình tham gia vào các cuộc thi $\mathrm{CDIO}$ Academy, nơi trưng bày và thi đấu các sản phẩm của sinh viên theo mô hình CDIO" - Đánh giá của ABET về điểm mạnh của chương trình đào tạo Công nghệ kỹ thuật Điện Điện tử tại Đại học Duy Tân.

\section{Outcome Based Education (OBE)}

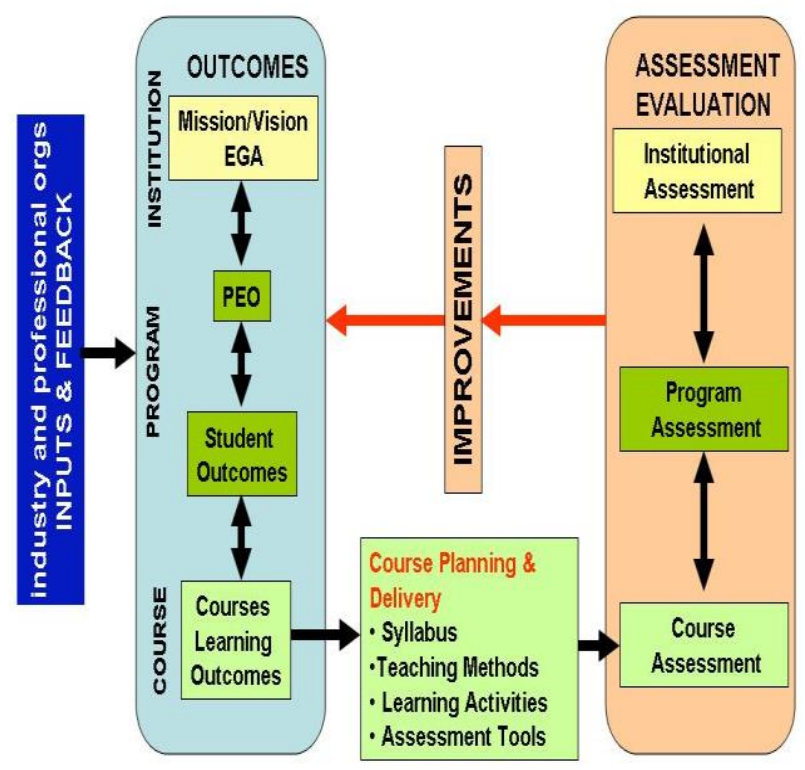

Hình 2. Mô hình đào tạo dụa trên chuẩn đầu ra (OBE)

Giáo dục dựa trên chuẩn đầu ra $(\mathrm{OBE})$ là một triết lý giáo dục dựa trên các thành phần của hệ thống giáo dục được điều hướng bởi các mục tiêu học tập (kết quả đầu ra) xung quanh. Ngay khi kết thúc một trải nghiệm học tập, người học kỳ vọng phải đạt được các mục tiêu học tập như đã được tuyên bố (cam kết). Không có một phương pháp giảng dạy hoặc đánh giá cụ thể nào được quy định cứng nhắc trong $\mathrm{OBE}$, thay vào đó, các bên liên quan làm tất cả mọi thứ để nhằm mục đích giúp người học đạt được các kết quả cụ thể. Giảng viên sẽ đóng vai trò là người hướng dẫn, đào tạo và tổ chức [6]. Triết lý xây dựng và đảm bảo chất lượng cho một chương trình đào tạo hướng đến chuẩn đầu ra được mô tả trong Hình 2. Có thể thấy rằng, có sự tương quan chặt chẽ giữa mô hình CDIO (các tiêu chuẩn $\mathrm{CDIO}$ ) với các khía cạnh của $\mathrm{OBE}$.

Mô hình giáo dục $\mathrm{OBE}$ nhấn mạnh đến khía cạnh rằng, các chương trình giáo dục cần hướng đến các chuẩn đầu ra một cách rõ ràng. Người học khi đó sẽ hiểu rằng các chuẩn đầu ra chính là các mong đợi của họ khi kết thúc một môn học hay một chương trình đào tạo. Và giảng viên cũng sẽ nhận thức được việc họ sẽ phải làm gì để giúp người học đạt được 
những điều đó. Các nguyên tắc này được phản ảnh một cách rõ ràng thông qua 2 câu hỏi lớn mà mô hình CDIO đã đề cập: 1) Người học cần có kiến thức, kỹ năng và thái độ gì khi tốt nghiệp đại học? Và ở mức độ thành thạo như thế nào?; 2) Làm thế nào để chúng ta có thể đảm bảo rằng người học sẽ đạt được những kỹ năng này? [7].

Những nội dung được trình bày bên dưới đây sẽ mô tả về các thách thức mà các chương trình đào tạo hiện nay ở Việt Nam đang gặp phải [8].

\subsection{Chuẩn đầu ra của Chuơng trình đào tạo và Chuẩn đầu ra của môn học}

Các chuẩn đầu ra của chương trình đào tạo được liệt kê và mô tả thường quá cụ thể. Một số chuẩn đầu ra được xây dựng theo từng khối và các khối con (như khối kiến thức chung, kiến thức cơ sở ngành, kiến thức chuyên ngành, kiến thức, kỹ năng, thái độ) do đó dẫn đến số lượng chuẩn đầu ra quá nhiều. Điều này sẽ gây thách thức và khó khăn cho việc đánh giá mức độ đáp ứng của người học đối với các chuẩn đầu ra khi kết thúc chương trình đào tạo. Các chương trình đào tạo dường như có sự nhầm lẫn giữa mục tiêu của chương trình đào tạo (Program Educational Objectives) với chuẩn đầu ra của chương trình (Program Outcomes/Student Outcomes).

Sự hiểu biết và áp dụng khái niệm chuẩn đầu ra cũng như triết lý giáo dục dựa trên chuẩn đầu ra giữa chương trình đào tạo và giảng viên vẫn còn nhiều hạn chế. Điều này được phản ánh rõ trong việc xây dựng và tuyên bố các chuẩn đầu ra ở cấp độ chương trình và ở cấp độ môn học. Một điều quan trọng hơn nữa là các chương trình đào tạo dường như thiếu sự hiểu biết rõ ràng về sự cần thiết và phương pháp đánh giá chuẩn đầu ra sau mỗi môn học cũng như khi kết thúc chương trình đào tạo.

Các tuyên bố về chuẩn đầu ra ở cấp độ môn học cần được cải thiện nhiều hơn nữa. Đối với hầu hết các môn học, việc xác định các chuẩn đầu ra dường như gặp những lỗi chung như: không thể đo lường được, quá nhiều chuẩn đầu ra, không được xác định một cách chính xác hoặc được xác định quá cụ thể. Khi tuyên bố các chuẩn đầu ra của môn học, giảng viên thường sử dụng các động từ để mô tả các năng lực của người học (kỳ vọng đạt được) một cách mơ hồ như: biết, hiểu, nắm vững, đánh giá cao, quen thuộc, nghiên cứu, nhận thức, làm quen với, đạt được kiến thức về, mong muốn, học hỏi, nhận ra. Làm thế nào để có thể đo lường được những năng lực này của người học?

\subsection{Chưong trình đào tạo}

Số lượng tín chỉ của các chương trình đào tạo dường như quá tải so với thời gian đào tạo. Các quan sát đã cho thấy rằng các chương trình đào tạo hều hết đều triển khai ở mức 145-150 tín chí cho thời gian đào tạo 4 năm (so với mặt bằng chung là 120 tín chỉ). Điều này có thể được giải thích là do khối lượng kiến thức giáo dục đại cương (general education) bao gồm các khối kiến thức theo quy định và kiến thức ngoại ngữ dường như chiếm một tỉ trọng lớn trong chương trình đào tạo. Các chương trình đào tạo thiếu vắng các học phần kết nối giữa mô-đun giáo dục đại cương với các mô-đun cơ sở ngành và chuyên ngành. Những phản ảnh cũng như đòi hỏi của người học về chương trình đào tạo thường xoay quanh các vấn đề như: các chương trình đào tạo nên dành nhiều thời gian hơn cho các học phần trọng tâm (core courses), giảm số tín chỉ cho mô-đun giáo dục đại cương. Người học luôn bày tỏ mong muốn được tiếp xúc sớm hơn với các môn học về nghiên cứu, các dự 
án có tính thực tế hơn và phản ảnh được mối liên hệ giữa các dự án với yêu cầu của doanh nghiệp, tăng cường và đa dạng các khóa học tự chọn từ các lĩnh vực liên quan.

Nhằm cung cấp một cái nhìn toàn cảnh cho người học về vai trò và trách nhiệm của người kỹ sư trong ngành nghề kỹ thuật, mô hình CDIO khuyến cáo nên đưa học phần Giới thiệu kỹ nghệ (Introduction to Engineering) vào ngay từ năm thứ nhất đối với chương trình đào tạo kỹ thuật (Tiêu chuẩn 4). Học phần giới thiệu kỹ nghệ nên là một trong những khóa học bắt buộc đầu tiên trong một chương trình đào tạo kỹ thuật. Nó cung cấp một mô hình tổng quan đầu tiên cho các thực hành về kỹ thuật trong ngành nghề liên quan. Các nội dung của học phần sẽ phác thảo về các nhiệm vụ và trách nhiệm của một người kỹ sư trong tương lai, cũng như việc áp dụng các kiến thức kỹ thuật chuyên môn trong việc thực hiện các nhiệm vụ của ngành nghề sau này. Người học được tham gia vào trải nghiệm ban đầu các thực hành về kỹ thuật thông qua việc giải quyết vấn đề, xử lý các bài tập thiết kế đơn giản theo cá nhân và theo nhóm [13].

\subsection{Phương pháp dạy và học}

Đề cương của các học phần không phản ánh được sự đa dạng của các phương pháp giảng dạy và các hoạt động học tập được sử dụng. Rất khó tìm thấy bằng chứng về sự phù hợp của các chiến lược giảng dạy - hoạt động học tập với hoạt động đánh giá kết quả học tập. Các phương pháp giảng dạy và hoạt động học tập thường chỉ đơn thuần là giảng bài, thực hành và tự học. Đề cương của các môn học cho thấy rằng phương pháp dạy và học chủ yếu vẫn dựa trên nội dung (content based) thay vì dựa trên kết quả đầu ra (outcome based).

\section{4. Đánh giá nguời học/Đánh giá năng lục của nguời học theo các chuẩn đầu ra}

Hầu hết các chương trình đào tạo hiện nay đều thiếu các bằng chứng về quá trình, phương pháp cũng như kết quả đánh giá năng lực của người học dựa theo các chuẩn đầu ra. Các hoạt động đánh giá thường chỉ tập trung vào kết quả học tập của người học khi thực hiện các bài kiểm tra hơn là đánh giá năng lực của người học so với các yêu cầu về chuẩn đầu ra. Làm thế nào để có thể đánh giá và phân biệt được các năng lực khác nhau của các người học khác nhau khi họ cùng đạt một mức điểm trong bài kiểm tra đánh giá? Các hoạt động kiểm tra đánh giá thường không cho thấy sự phù hợp của các phương pháp đánh giá cũng như các câu hỏi dùng để đánh giá với các chuẩn đầu ra như đã tuyên bố. Vấn đề này có nguyên nhân sâu xa là do các trường đang vận hành một chương trình đào tạo quá tải, số lượng người học trong một lớp vượt khỏi khả năng kiểm soát của giảng viên, giảng viên bị quá tải bởi các công việc khác thay vì tập trung vào công tác giảng dạy và đánh giá người học.

Ngay cả trong bản thân đội ngũ giảng dạy, dường như cũng chưa có sự nhận thức về việc mỗi chuẩn đầu ra của môn học, của chương trình cần phải được đánh giá. Việc nâng cao nhận thức của đội ngũ giảng dạy về sự cần thiết của việc giảng dạy và đánh giá theo chuẩn đầu ra là điều kiện quan trọng cho việc xác định các kết quả đạt được và chưa đạt được của chương trình đào tạo nhằm làm cơ sở cho các hành động cải tiến. Việc xác định mức độ đạt được chuẩn đầu ra của từng người học là cơ sở quan trọng cho những hành động cải tiến chương trình đào tạo. Đây là hoạt động phù hợp với chu trình PDCA (PlanDo-Check-Action) trong mô hình đào tạo dựa trên chuẩn đầu ra.

\section{5. Đảm bảo chất lự̣ng}


Tiêu chí AUN 2.11.4 yêu cầu chương trình giảng dạy phải được đánh giá thường xuyên trong những khoảng thời gian hợp lý. Thông thường, thời gian để thực hiện các hoạt động đánh giá và cải tiến diễn ra trong khoảng thời gian mà chương trình đào tạo vận hành. Việc điều chỉnh, cải tiến các môn học có thể được thực hiện trong quá trình thực hiện chương trình đào tạo nhằm giải quyết các yêu cầu tức thì (như các thay đổi về công nghệ có liên quan đến các môn học chẳng hạn). Tuy nhiên việc sửa đổi quá thường xuyên có vẻ sẽ phản tác dụng và chắp vá khi không có đánh giá tổng thể về toàn bộ chương trình đào tạo. Hơn nữa, quá trình xem xét các hành động cải tiến nhỏ lẻ sẽ làm tăng thêm áp lực đối với giảng viên và đội ngũ đánh giá chương trình đào tạo.

\section{Kiểm định $\mathrm{ABET}$ và các kiểm định khác là động lực}

Mô hình $\mathrm{CDIO}$ được đề xướng với mục tiêu nhằm cung cấp cho các cơ sở giáo dục một bộ công cụ mạnh mẽ về đảm bảo chất lượng bên trong chứ không chỉ đơn thuần là để kiểm định chất lượng chương trình đào tạo [1]. Tuy nhiên, trong bối cảnh hiện trạng các trường đại học ở Việt Nam hiện nay, động lực để đổi mới chương trình đào tạo (theo $\mathrm{CDIO})$ có lẽ nên được gắn liền với hoạt động kiểm định (ABET là một ví dụ). Chiến lược này giúp việc vận dụng các nguyên tắc của CDIO được thực thi đầy đủ và đánh giá được độ hiệu quả của quá trình áp dụng trên thực tế [9].

Do dựa trên triết lý của $\mathrm{OBE}$ cũng như các yêu cầu đổi mới từ chính các doanh nghiệp kỹ thuật, mô hình CDIO có tính tương thích mạnh mẽ với các tiêu chuẩn về kiểm định các chương trình đào tạo kỹ thuật trên thế giới. Bảng 1 . mô tả sự tương quan giữa các gợi ý về chuẩn đầu ra theo CDIO với các yêu cầu về chuẩn đầu ra cho các chương trình kỹ thuật theo kiểm định ABET. Bảng 2. mô tả sự tương quan giữa các gợi ý về chuẩn đầu ra theo CDIO với các yêu cầu về chuẩn đầu ra cho các chương trình kỹ thuật theo kiểm định CEAB (Canadian Engineering Accreditation Board). Bảng 3. mô tả sự tương quan giữa các gợi ý về chuẩn đầu ra theo CDIO với các yêu cầu về chuẩn đầu ra cho các chương trình kỹ thuật theo kiểm định EUR-ACE (European Accredited Engineer). Bảng 4. mô tả sự tương quan giữa các yêu cầu về chuẩn đầu ra cho các chương trình kỹ thuật theo kiểm định $\mathrm{ABET}$ với chuẩn yêu cầu năng lực tối thiểu đối với trình độ đại học ở Việt Nam.

Bảng 1. Tưong quan giũua CDIO Syllabus với Chuẩn đầu ra ABET 


\begin{tabular}{|c|c|c|c|c|c|c|c|c|c|c|c|c|c|c|c|c|c|}
\hline $\begin{array}{c}\text { EUR-ACE Syllabus } \\
\text { (EURopean- } \\
\text { ACcredited Engineer) }\end{array}$ & \multicolumn{10}{|c|}{ CDIO Syllabus Level X.X. } \\
\hline & 1.1 & 1.2 & 1.3 & 2.1 & 2.2 & 2.3 & 2.4 & 2.5 & 3.1 & 3.2 & 3.3 & 4.1 & 4.2 & 4.3 & 4.4 & 4.5 & 4.6 \\
\hline 1.1 & $\mathrm{X}$ & $\mathrm{X}$ & & & & & & & & & \\
\hline
\end{tabular}

Bảng 4. Tưong quan giũ̃a Chuẩn đầu ra theo ABET và Chuẩn năng lục Đại học (Việt Nam)

\begin{tabular}{|c|c|c|}
\hline Stt & $\begin{array}{c}\text { Chuẩn đầu ra đối với các ngành kỹ } \\
\text { thuật (ABET) }\end{array}$ & $\begin{array}{l}\text { Chuẩn yêu cầu năng lực tối thiểu ở trình độ Đại học } \\
\text { (Việt Nam) }\end{array}$ \\
\hline 1 & $\begin{array}{l}\text { (a) khả năng áp dụng kiến thức về toán } \\
\text { học, khoa học và kỹ thuật để giải quyết } \\
\text { các bài toán trong lĩnh vực... }\end{array}$ & $\begin{array}{l}\text { Có kiến thức lý thuyết chuyên sâu trong lĩnh vực đào tạo; } \\
\text { Nắm vững kỹ thuật và có kiến thức thực tế để có thể giải } \\
\text { quyết các công việc phức tạp; }\end{array}$ \\
\hline 2 & $\begin{array}{l}\text { (b) khả năng thiết kế và tiến hành các } \\
\text { thực nghiệm, cũng như phân tích và } \\
\text { diễn giải dữ liệu }\end{array}$ & $\begin{array}{l}\text { Có kỹ năng phân tích, tổng hợp, đánh giá dữ liệu và thông } \\
\text { tin, tồng hợp ý kiến tập thề và sử dụng những thành tựu } \\
\text { mới về khoa học công nghệ để giải quyết những vấn đề } \\
\text { thực tế hay trừu tượng trong lĩnh vực được đào tạo; }\end{array}$ \\
\hline 3 & $\begin{array}{l}\text { (c) khả năng thiết kế một hệ thống, } \\
\text { thành phần, hoặc quy trình để đáp ứng } \\
\text { nhu cầu mong muốn trong điều kiện } \\
\text { ràng buộc của thực tế như kinh tế, môi } \\
\text { trường, xã hội, chính trị, đạo đức, sức } \\
\text { khỏe và an toàn, khả năng sản xuất } \\
\text { được, và tính bền vững }\end{array}$ & $\begin{array}{l}\text { Có kỹ năng hoàn thành công việc phức tạp đòi hỏi vận } \\
\text { dụng kiến thức lý thuyết và thực tiễn của ngành được đào } \\
\text { tạo trong những bối cảnh khác nhau; }\end{array}$ \\
\hline 4 & $\begin{array}{l}\text { (d) khả năng làm việc hiệu quả trong } \\
\text { các các nhóm đa ngành, đa lînh vực }\end{array}$ & $\begin{array}{l}\text { Có năng lực lập kế hoạch, điều phối, phát huy trí tuệ tập } \\
\text { thể; } \\
\text { Có năng lực dẫn dắt chuyên môn để xử lý những vấn đề } \\
\text { quy mô địa phương và vùng miền; } \\
\text { Có năng lực dẫn dắt về chuyên môn, nghiệp vụ đã được } \\
\text { đào tạo; }\end{array}$ \\
\hline 5 & $\begin{array}{l}\text { (e) khả năng xác định, xây dựng, và giải } \\
\text { quyết các vấn đề kỹ thuật trong lĩnh } \\
\text { vực... }\end{array}$ & $\begin{array}{l}\text { Có khả năng đưa ra được kết luận về các vấn đề chuyên } \\
\text { môn, nghiệp vụ thông thường và một số vấn đề phức tạp } \\
\text { về mặt kỹ thuật; }\end{array}$ \\
\hline 6 & $\begin{array}{l}\text { (f) hiểu biết về trách nhiệm và đạo đức } \\
\text { nghề nghiệp }\end{array}$ & $\begin{array}{l}\text { Các yêu cầu chung về đạo đức nghề nghiệp, thái độ tuân } \\
\text { thủ các nguyên tắc an toàn nghề nghiệp, trình độ lỳ luận } \\
\text { chính trị,, kiến thức quốc phòng - an ninh theo quy định } \\
\text { hiện hành }\end{array}$ \\
\hline 7 & $\begin{array}{l}\text { (g) khả năng giao tiếp hiệu quả (bao } \\
\text { gồm năng lực ngoại ngữ) }\end{array}$ & $\begin{array}{l}\text { Có kỹ năng ngoại ngữ ở mức có thể hiểu được các ý chính } \\
\text { của một báo cáo hay bài phát biểu về các chủ đề quen } \\
\text { thuộc trong công việc liên quan đến ngành được đào tạo; }\end{array}$ \\
\hline
\end{tabular}




\begin{tabular}{|c|c|c|}
\hline & & $\begin{array}{l}\text { có thể sử dụng ngoại ngữ để diễn đạt, xử lý một số tình } \\
\text { huống chuyên môn thông thường; có thể viết được báo } \\
\text { cáo có nội dung đơn giản, trình bày ý kiến liên quan đến } \\
\text { công việc chuyên môn; }\end{array}$ \\
\hline 8 & $\begin{array}{l}\text { (h) hiểu biết rộng rãi để hiểu được tác } \\
\text { động của các giải pháp kỹ thuật trong } \\
\text { bối cảnh toàn cầu hóa, kinh tế, môi } \\
\text { trường và xã hội }\end{array}$ & $\begin{array}{l}\text { Có kiến thức quản lý, điều hành, kiến thức pháp luật và } \\
\text { bảo vệ môi trường liên quan đến lĩnh vực được đào tạo; }\end{array}$ \\
\hline 9 & $\begin{array}{l}\text { (i) nhận thức về sự cần thiết và khả năng } \\
\text { tham gia học tập suốt đời }\end{array}$ & $\begin{array}{l}\text { Tự học tập, tích lũy kiến thức, kinh nghiệm để nâng cao } \\
\text { trình độ chuyên môn nghiệp vụ; } \\
\text { Có khả năng tự định hướng, thích nghi với các môi trường } \\
\text { làm việc khác nhau; } \\
\text { Tích luỹ được kiến thức nền tảng về các nguyên lý cơ bản, } \\
\text { các quy luật tự nhiên và xã hội trong lĩnh vực được đào } \\
\text { tạo để phát triển kiến thức mới và có thể tiếp tục học tập ở } \\
\text { trình độ cao hơn; }\end{array}$ \\
\hline 10 & $\begin{array}{l}\text { (j) sự hiểu biết về các vấn đề thời sự, } \\
\text { đương đại trong lĩnh vực... }\end{array}$ & \\
\hline 11 & $\begin{array}{l}\text { (k) khả năng sử dụng các kỹ thuật, kỹ } \\
\text { năng và công cụ kỹ thuật hiện đại nhằm } \\
\text { phục vụ cho việc thực hành kỹ thuật } \\
\text { trong lĩnh vực... }\end{array}$ & $\begin{array}{l}\text { Chuẩn kỹ năng sử dụng công nghệ thông tin cơ bản theo } \\
\text { quy định hiện hành vể Chuân kỹ năng sử dụng công nghệ } \\
\text { thông tin do Bộ Thông tin và Truyền thông ban hành }\end{array}$ \\
\hline 12 & & $\begin{array}{l}\text { Có sáng kiến trong quá trình thực hiện nhiệm vụ được } \\
\text { giao; }\end{array}$ \\
\hline 13 & & $\begin{array}{l}\text { Có năng lực đánh giá và cải tiến các hoạt động chuyên } \\
\text { môn ở quy mô trung bình. }\end{array}$ \\
\hline
\end{tabular}

\section{5. Đánh giá chương trình đào tạo theo chuẩn đầu ra}

\subsection{Tiêu chuẩn 11 - CDIO Standards}

Đánh giá kết quả học tập của người học là thước đo mức độ mà mỗi học sinh đạt được năng lực cụ thể. Giảng viên thực hiện công tác đánh giá này trong các môn học mà họ phụ trách. Nếu các chương trình đào tạo coi trọng các kỹ năng cá nhân, giữa các cá nhân, cũng như các kỹ năng về xây dựng và phát triển một sản phẩm, quy trình và hệ thống, đồng thời đưa chúng vào chương trình giảng dạy và trải nghiệm học tập, thì chúng ta phải có các quy trình đánh giá hiệu quả để đo lường chúng [10].

Các chuẩn năng lực đầu ra khác nhau đòi hỏi sử dụng các phương pháp đánh giá khác nhau. Ví dụ, các chuẩn đầu ra liên quan đến các kiến thức và năng lực ngành nghề có thể được đánh giá bằng các bài kiểm tra nói và viết, trong khi các chuẩn đầu ra liên quan đến các kỹ năng triển khai, thiết kế có thể được đo lường tốt hơn bằng các quan sát, trình bày, hỏi đáp, hoặc các Rubrics.

\subsection{ABET - Tiêu chuẩn 4. Cải tiến liên tục}

Chương trình đào tạo phải thường xuyên sử dụng các quy trình thích hợp, minh chứng về các công cụ đánh giá và đánh giá được mức độ đạt của người học đối với các chuẩn đầu ra. Kết quả của những đánh giá này phải được sử dụng một cách có hệ thống làm đầu vào cho việc cải tiến liên tục chương trình đào tạo [11]. 


\subsection{AUN-QA - Tiêu chuẩn 5. Kiểm tra, đánh giá nguời học}

AUN-QA quy định về việc cần phải đánh giá năng lực người học phù hợp với các chuẩn đầu ra của chương trình đào tạo.

Để đảm bảo sự tương thích có định hướng, nhà trường cần áp dụng đa dạng các phương pháp kiểm tra, đánh giá phù hợp với các chuẩn đầu ra của chương trình đào tạo/Chuẩn đầu ra của môn học. Hoạt động kiểm tra, đánh giá cần đo được mức độ đạt được chuẩn đầu ra của chương trình đào tạo/môn học.

Sử dụng đa dạng các phương pháp kiểm tra đánh giá một cách có hệ thống để phục vụ các mục đích đánh giá khác nhau.

Công tác đánh giá chương trình đào tạo theo chuẩn đầu ra là một quá trình đòi hỏi nhiều nỗ lực của các cơ sở giáo dục. Quá trình này luôn gặp thách thức khi số lượng người học trong một chương trình đào tạo quá đông, hoặc khi cơ sở giáo dục cung cấp các học phần chung cho nhiều chương trình đào tạo. Hình 3 mô tả về chiến lược sử dụng hiệu quả các hình thức khác nhau trong quá trình đánh giá mục tiêu và chuẩn đầu ra của chương trình đào tạo. Việc xây dựng một hệ thống đánh giá điện tử cũng là một trong những cách tiếp cận hiệu quả trong quá trình đánh giá năng lực người học theo chuẩn đầu ra [12]. Một hệ thống như vậy sẽ hỗ trợ đắc lực cho giảng viên và chương trình đào tạo trong việc đánh giá năng lực người học và triển khai các chương trình đào tạo theo chuẩn đầu ra hay theo CDIO.

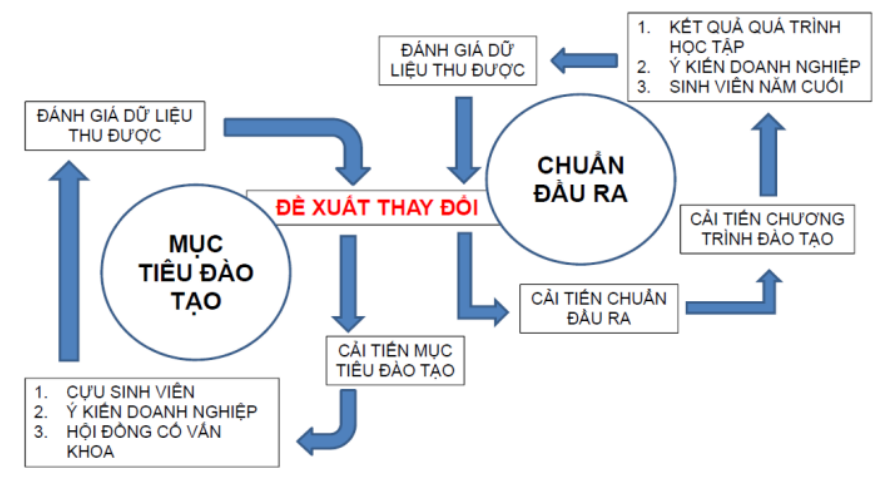

Hình 3. Mô hình đánh giá mục tiêu và chuẩn đầu ra của chuoong trình đào tạo

\section{Kết luận}

Vận dụng mô hình CDIO trong quá trình cải tiến các chương trình đào tạo kỹ thuật là một quá trình đòi hỏi nhiều nguồn lực và sự quyết tâm từ phía các cơ sở giáo dục. Một chương trình đào tạo được triển khai hiệu quả chắc chắn cần dựa trên nền tảng xác định đúng đắn các bối cảnh từ đó xác định rõ ràng các mục tiêu đào tạo và chuẩn đầu ra phù hợp. Nâng cao nhận thức và sự hiểu biết của đội ngũ về giáo dục OBE là chìa khóa quan trọng để triển khai hiệu quả mô hình CDIO.

Các quy định của pháp luật Việt Nam hiện nay đang tạo điều kiện thuận lợi để các cơ sở giáo dục tự đổi mới chương trình đào tạo theo hướng tương thích với các chương trình đào tạo của các đại học uy tín trên thế giới thông qua các hoạt động kiểm định quốc tế. Việc 
tham gia kiểm định bởi các tổ chức kiểm định quốc tế được công nhận rộng rãi trên thế giới (như $\mathrm{ABET}$ ) sẽ là động lực giúp cho quá trình triển khai CDIO được đi vào thực tiễn. Các kết quả kiểm định đó cũng giúp các chương trình đào tạo tại Việt Nam có điều kiện để tham gia vào các Hiệp định công nhận văn bằng lẫn nhau như Washington Accord, Seoul Accord, Canberra Accord. Điều này cũng tạo thêm nhiều cơ hội cho người tốt nghiệp khi tham gia vào thị trường lao động quốc tế hay học tập sau đại học tại các nước trên thế giới.

\section{Tài liệu tham khảo}

[1] http://cdio.org.

[2] CDIO Standards. Standard 1 - The Context.

[3] ABET Criteria for Accrediting Engineering Programs. Standard 5 - Curriculum.

[4] CDIO Standards. Standard 3 - Integrated Curriculum.

[5] CDIO Standards. Standard 5 - Design-Implement Experiences.

[6] Spady, William (1994). Outcome-Based Education: Critical Issues and Answers. Arlington Virginia: American Association of School Administrators.

[7] Crawley, E.F., Malmqvist, J., Östlund, S., Brodeur, D.R. Rethinking Engineering Education.The CDIO Approach. Springer; 2nd ed. 2014 edition.

[8] AUN-QA Reports. AUN Assessment at Programme Level. 2016.

[9] Nguyen Gia Nhu, Le Nguyen Bao, Nguyen Thanh Trung. CDIO as the foundations for international accrediations. Proceedings of the 9th International CDIO Conference, Massachusetts Institute of Technology and Harvard University School of Engineering and Applied Sciences, Cambridge, Massachusetts, June 9-13, 2013.

[10]CDIO Standards. Standard 11 - Learning Assessment.

[11]ABET Criteria for Accrediting Engineering Programs. Standard 4 - Continuous Improvement.

[12]Tran Nhat Tan, Le Nguyen Bao. Showcase of an automatic assessment system for students's performance and accrediatation. Proceedings of the CDIO Asian Regional Meeting. 13 - 15 March 2017. Thailand.

[13]CDIO Standards. Standard 4 - Introduction to Engineering. 